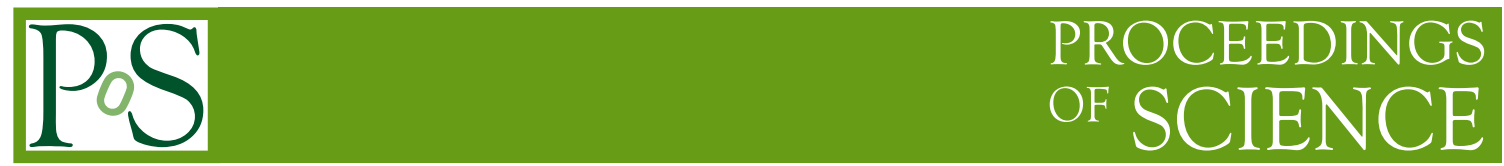

\title{
Geometric Unification
}

\section{Ali Chamseddine*}

American Univ. of Beirut and Inst. des Hautes Etudes Scientifiques

E-mail: chams eaub.edu. lb

I will show that Noncommutative Geometry provides an appealing framework for the unification of all fundamental interactions including gravity

Frontiers of Fundamental Physics 14 - FFP14,

15-18 July 2014

Aix Marseille University (AMU) Saint-Charles Campus, Marseille

${ }^{*}$ Speaker. 